\title{
Diretrizes Curriculares e projetos pedagógicos: é tempo de ação! $\dagger$
}

\section{A importância das Diretrizes Curriculares Nacionais na formação dos profissionais da Odontologia deve ser amplamente discutida.}

\author{
Laura Feuerwerker*, Márcio Almeida**
}
* Médica, Coordenadora Geral de Ações Estratégicas de Educação na Saúde da Secretaria de Gestão do Trabalho e da Educação na Saúde, Ministério da Saúde.
** Médico, Professor da Universidade Estadual de Londrina, Coorde- nador da Secretaria Executiva da Rede UNIDA.

\section{RESUMO}

O texto aponta o teor analítico do artigo "Diretrizes Curriculares e projetos pedagógicos” que abre a seção de debates da REBEn (Revista Brasileira de Enfermagem). Faz crítica a sua temporalidade e ao fato de não ser propositivo. Comenta a opinião das autoras em relação à formulação das diretrizes e seu contexto opinando sobre o que expressam em relação à mudanças na formação dos profissionais de Saúde. Ao longo do texto os autores expõem sua opinião favorável ao modo como foram construídas as Diretrizes Curriculares Nacionais, destacando o contexto político em que devem ser interpretadas e que supõem que serão implementadas.

\section{DESCRITORES}

Diretrizes Curriculares Nacionais. Currículos de enfermagem. Educação em enfermagem.

$\mathbf{0}$ texto de Meyer, Kruse é analítico e crítico e aponta questões relevantes para o debate acerca da formação de Enfermagem (e dos profissionais da Saúde) em nosso País. Perde forças, no entanto, ao ser publicado um ano e meio após ser escrito e também ao não entrar no campo das proposições, num momento em que as escolas estão se mobilizando em torno da necessidade de mudanças.

Vale a pena, muito brevemente, comentar alguns dos temas levantados pelas autoras. Em primeiro lu- gar, dizer que as Diretrizes Curriculares expressam uma orientação geral, algumas vezes genérica, justamente porque não pretendem ser a expressão de um Currículo Nacional. As orientações das Diretrizes estimulam as escolas a superar as concepções conservadoras, a rigidez, o conteudismo e as prescrições estritas existentes nos Currículos Mínimos, mas não definem um caminho único.

Objetivamente, ao interior das formulações expressas nas Diretrizes, há espaço para que as escolas, como convidam as autoras "no exercício de sua autonomia”, formulem e organizem seus projetos pedagógicos, elejam estratégias e modos de fazer

\footnotetext{
“articulados, ao mesmo tempo, às demandas políticas $\mathrm{e}$ sociais da sociedade brasileira mais ampla e às necessidades e interesses dos 'locais' onde se inserem de modo a reordenar a formação dos recursos humanos em saúde que contemple práticas sanitárias relacionadas a um conceito ampliado de saúde e de justiça social”.
}

Em segundo lugar, o contexto em que foram definidas as Diretrizes Curriculares no Brasil não pode ser omitido. Ou seja, se de maneira genérica a orientação das políticas educacionais no Brasil nos últimos anos esteve sintonizada com as definições dos organismos internacionais no caso das Diretrizes Curriculares houve uma efetiva modulação que as aproximassem das orientações do sistema público de saúde (público,

† Artigo transcrito da Revista Brasileira de Enfermagem 2003;56(4):351-2. 
democrático, em busca da universalidade e da integralidade da atenção). Não seria o nosso o único caso em que no contexto da globalização, uma proposição de reforma universitária conseguiria escapar das tendências racionalizadoras orientadas ao mercado e à competição ${ }^{1}$.

De um modo geral, as Diretrizes expressam o compromisso dos movimentos por mudanças na formação dos profissionais de Saúde com compreensão ampla do que significa currículo, considerando que ele deva expressar posicionamento da universidade diante de seu papel social dos conceitos de saúde e educação etc. Não por outra razão aparece explícita a necessidade de a formação estar claramente comprometida e direcionada à concentração dos princípios da Reforma Sanitária Brasileira e do Sistema Único de Saúde (SUS). É nesse contexto que muitas das formulações genéricas devem ser interpretadas.

Certas imprecisões do texto das Diretrizes Curriculares no entanto refletem a existência de disputa em torno da orientação das futuras mudanças. Há um convite à formação por competência - o que, em si, tem um aspecto positivo ao indicar a necessidade de experiências e oportunidades de ensino-aprendizagem que possibilitem o desenvolvimento para além do campo cognitivo. No entanto, em torno da definição de competência e das maneiras de desenvolvê-las há um intenso debate em torno de orientações behavioristas e construtivas (para citar apenas algumas delas). As Diretrizes não explicam as diferenças, nem tampouco sugerem uma ou outra opção. Deixam a questão em aberto, mas indicam, sim, especialmente nas competências comuns a todos os profissionais de Saúde a necessidade de trabalhar em campos como a comunicação, o trabalho em equipe etc.

$\mathrm{O}$ convite à interdisciplinaridade também não pode deixar de ser reconhecido como avanço e como passo indispensável à superação dos currículos organizados por disciplinas e centrados nos conteúdos. Em nenhum lugar as Diretrizes indicam ser simples essa superação.

É fato que as Diretrizes não indicam com precisão se os conteúdos e experiências de aprendizagem devem ser orientados, por exemplo, pelas necessidades dos estudantes ou pelas necessidades de aprendizagem articuladas às necessidades sociais. Mencionam a necessidade da aprendizagem ativa e a necessidade de tratar dos problemas da realidade: ou seja, deixam em aberto o tipo de orientação a ser adotado em cada escola, mas sugerem a superação das abordagens tradicionais.
Por fim, é verdade que as Diretrizes não indicam os caminhos que as escolas devem percorrer para chegar às transformações necessárias. Mas os movimentos de mudança na educação dos profissionais de Saúde vêm acumulando experiência e conhecimento a respeito. Sabemos que essas orientações podem propiciar processos de mudanças profundos, necessariamente baseados na constituição de sujeitos, na democratização das escolas e no crescimento de seu compromisso social. Mas, como as orientações são genéricas, também comportam mudanças mais tímidas, circunscritas. A avaliação, portanto, cumprirá papel fundamental no processo de orientação das mudanças.

É verdade que o Ministério da Educação e Cultura (MEC), no governo anterior, não havia atualizado os mecanismos de avaliação (dos estudantes, das condições de ensino e do corpo docente) para que houvesse coerência entre Diretrizes Curriculares e avaliação. Ou para que a avaliação servisse como uma ferramenta para alimentar e orientar as mudanças em curso. Mas também é verdade que o movimento de mudanças estava aberto para estas contradições e buscava caminhos para produzir sua superação.

É na falta de atualização na avaliação de contexto, entretanto, que $o$ artigo perde força. Existe, atualmente, por parte do novo governo, uma política que explicitamente indica e estimula uma orientação clara para as necessárias mudanças na formação dos profissionais de Saúde. Estão sendo propostos, pelo Ministério da Saúde, fóruns que devem possibilitar o diálogo entre instituições formadoras, gestores do sistema de saúde e representantes do controle social para definir os caminhos que a formação deve percorrer para atender às necessidades do SUS. Está sendo oferecido apoio técnico e financeiro para o desenvolvimento das mudanças na formação que adotem expressamente essa orientação.

Por último, é importante ressaltar que durante o processo de construção das mudanças é necessário construir e preservar os espaços coletivos para debates e reflexões críticas ${ }^{2}$, sobretudo porque os desafios são muitos e as áreas de desconhecimento também são freqüentes. Desafios como a ampliação da clínica, a articulação entre indivíduos e coletivo, a construção da integralidade da atenção, do trabalho em equipes matriciais, por exemplo, estão postos simultaneamente para as escolas e para o sistema de saúde. E deverão ser enfrentados conjuntamente no processo de transformação do processo de formação e das práticas de saúde. 
O momento atual exige convite e orientação à reflexão, mas, sobretudo, à ação! E esse convite não está claramente expresso no artigo.

\section{ABSTRACT}

Curricular Guidelines and pedagogical projects: it's time to act!

This text considers the analytical content of the article "Curricular Guidelines and pedagogical projects", which opens the debate section at REBEn (Brazilian Review of Nursing). It criticizes its provisional character and the fact that it is not propositional. It provides comments from the authors regarding the design of guidelines and their content when it comes to the education of health professionals. Throughtout their text, the authors express their agreement with the manner in which the National Curricular Guidelines have been created in Brazil, stressing the need to interpret them within their political context and the manner in which they will supposedly be implemented.

\section{DESCRIPTORS}

National Curricular Guidelines. Nursing curricula. Education, nursing. -

\section{REFERÊNCIAS BIBLIOGRÁFICAS}

1. Afonso AJ. Avaliação educacional: regulação e emancipação: para uma sociologia das políticas avaliativas contemporâneas. São Paulo: Cortez; 2000

2. Feuerwerker L. Além do discurso de mudança na educação médica: processos e resultados. São Paulo: Hucitec; 2002.

Aceito para publicação em 11/2003

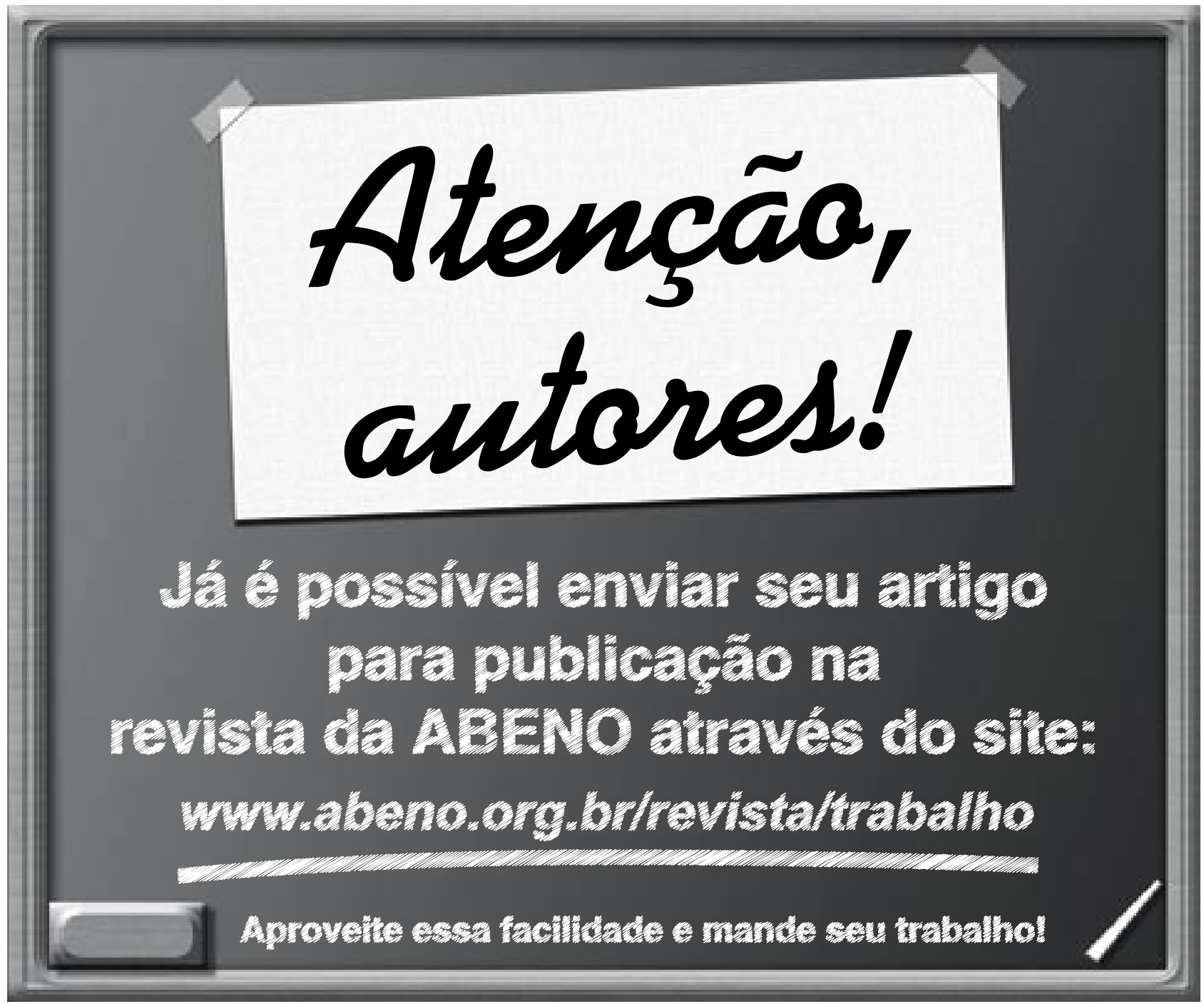

